\title{
THE RELATIVE VALUES OF THE KAHN AND WASSERMANN REACTION BASED UPON A SURVEY OF I75 CLINICAL CASES AND TESTS UPON 5,000 SERA
}

By Dr. L. W. CANN and Dr. S. De NAVASQUEZ

IT was decided, after a number of preliminary tests, in January, I929, to perform the Kahn test for syphilis in conjunction with the Wassermann reaction whenever the quantity of serum received would permit this double procedure. During that year (I929), 5,000 sera were subjected to collateral tests, and the figures given below will add to the already extensive evidence in favour of Kahn's precipitation method.

We were persuaded, however, to publish the results of our investigations, not for the simple comparative figures, but because the clinical records of many of the cases attending the Venereal Diseases Clinic, Guy's Hospital, were at our disposal and made it possible to trace, in a number of patients, the results of treatment upon these two reactions.

There is at present little published information upon the correlation of the Kahn reaction with the clinical progress of cases of syphilis.

All the results recorded were obtained with the " routine test" as described by Kahn. We have not, as yet, used the presumptive, quantitative, and special cerebro-spinal-fluid procedures.

At the end of twelve months we were sufficiently impressed with our results to adopt the Kahn test as a routine measure in conjunction with the Wassermann reaction upon all sera received in the department.

\section{Comparative Figures}

We have set out, firstly, the comparative results of the two tests as upon a series of sera of unknown origin. This is supplemented by repeat tests upon the same sera 


\section{BRITISH JOURNAL OF VENEREAL DISEASES}

which showed discrepancies in the two reactions, whenever the quantity of serum would permit.

The maximum reading with the Kahn test is ++++ . In the following tables a positive reaction includes ++ ; +++ ; or ++++ ; a doubtful reaction + .

As a routine we report our Wassermann reactions with a maximum reading of ++ , but for the purposes of this paper we have interpreted this strong positive Wassermann $(++)$ as a ++++ . This facilitates comparison.

Comparative Findings of Wassermann and Kahn Tests with 5,000 Sera

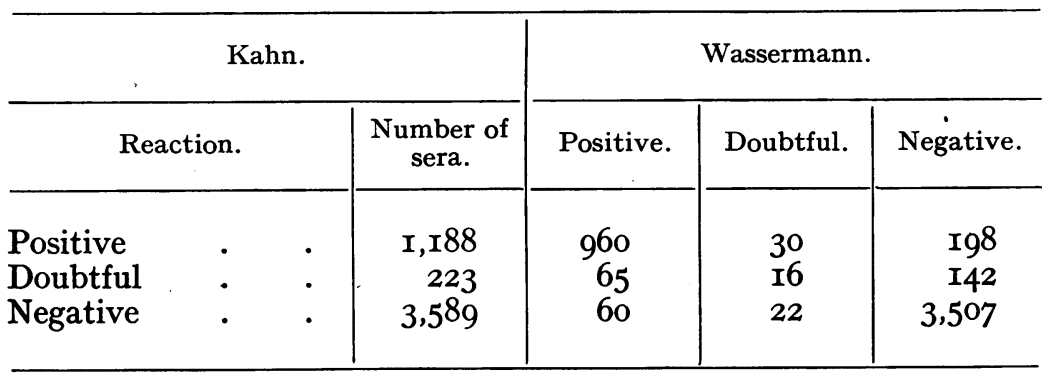

Per cent. Check of Kahn Test with Wassermann

\begin{tabular}{c|c|c|c}
\hline $\begin{array}{c}\text { Total sera } \\
\text { examined. }\end{array}$ & Absolute check. & Relative check. & No check. \\
\cline { 1 - 2 } 5,000 & $89 \cdot 66$ & $5 \cdot 18$ & $5 \cdot 16$ \\
\hline
\end{tabular}

These figures, although in a measure highly satisfactory, compare unfavourably with some of those published by Kahn, which are as follows :-

Comparative Check of Kahn Test with Wassermann

\begin{tabular}{c|c|c|c}
\hline $\begin{array}{c}\text { Total sera } \\
\text { examined. }\end{array}$ & Absolute check. & Relative check. & No check. \\
\hline 58,170 & 97.64 & $2 \cdot 15$ & $0 \cdot 2 \mathrm{I}$ \\
\hline
\end{tabular}

We have no other explanation to offer than that our relatively small experience with the Kahn test has meant Io6 


\section{KAHN AND WASSERMANN REACTION}

some slight inconsistency in the interpretation of our results. It is also of considerable importance that when repeat tests were performed upon sera giving no check with the two reactions, the discrepancies, especially those of a major nature, became greatly reduced in number. In most cases this was due to a change in the second Wassermann test which approached to the more consistent Kahn results. In the performance of these repeat tests we took precautions which made it impossible for us to know the original reactions of any particular serum. There was thus no risk of biassed readings.

Results of Repeat Tests

Group I.-First Kahn Negative

\begin{tabular}{|c|c|c|c|c|c|c|c|c|c|c|c|c|}
\hline \multirow{2}{*}{ 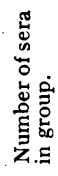 } & \multirow{2}{*}{ 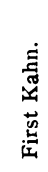 } & \multirow{2}{*}{$\begin{array}{c}\text { First } \\
\text { Wassermann. }\end{array}$} & \multicolumn{5}{|c|}{ Repeat Wassermann. } & \multicolumn{5}{|c|}{ Repeat Kahn. } \\
\hline & & & - & + & ++ & +++ & ++++ & - & + & ++ & +++ & ++++ \\
\hline 22 & - & + & I6 & - & I & - & - & I & - & - & 一 & - \\
\hline 52 & - & $\begin{array}{c}++ \\
\text { or } \\
++\end{array}$ & 30 & 6 & 4 & I & - & 4 & 2 & - & - & - \\
\hline 8 & - & ++++ & 2 & I & 2 & - & - & I & I & - & - & - \\
\hline
\end{tabular}

Group II.-First Wassermann Negative

\begin{tabular}{|c|c|c|c|c|c|c|c|c|c|c|c|c|}
\hline \multirow{2}{*}{ 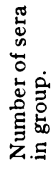 } & \multirow{2}{*}{ First Kahn. } & \multirow{2}{*}{ 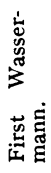 } & \multicolumn{5}{|c|}{ Repeat Wassermann. } & \multicolumn{5}{|c|}{ Repeat Kahn. } \\
\hline & & & - & + & ++ & $++t$ & +++ & 一 & + & ++ & $+t+$ & +++ \\
\hline I 42 & + & 一 & 102 & 5 & 7 & 2 & - & $2 \mathrm{I}$ & 22 & I & - & - \\
\hline I 12 & ++ & 一 & 55 & 8 & 8 & 3 & 5 & I I & I 2 & 8 & - & - \\
\hline 64 & $+t+$ & - & 23 & 7 & 7 & 4 & I 2 & 4 & - & 8 & 6 & 2 \\
\hline 22 & $++t+$ & 一 & 6 & I & 3 & 2 & 6 & - & I & - & 5 & 一 \\
\hline
\end{tabular}

In these charts it will be seen that the number of repeat tests is always less than the original number of cases in any particular group. In many cases there was insufficient serum to repeat one or both tests. It was the routine to give preference to the repeat Wassermann 


\section{BRITISH JOURNAL OF VENEREAL DISEASES}

reaction, and these are thus more numerous than the Kahns.

A careful perusal of these figures will show the following points :-

(I) That in the original 5,000 tests there were four times as many sera that gave a positive Kahn result with a negative Wassermann as those which gave a negative Kahn with a positive Wassermann.

(2) When the test is repeated the Wassermann reaction shows a definitely higher percentage of differences, especially gross differences, than does the Kahn. These second results showing change are generally in favour of the original Kahn result.

This is especially marked in the groups of originally negative Kahns and positive Wassermanns $(++;+++$; or ++++ ), in which group 46 originally positive Wassermanns gave with repeat tests 32 negative, 7 doubtful and 9 positive results. Unfortunately, the number of Kahns in this group that we were able to repeat is insignificant.

(3) The repeated Kahn tests, although much smaller in number, are sufficient to conclude that differences, although frequent, are mostly of a minor nature. (This conclusion is confirmed by a large number of repeated Kahns performed subsequently to those included in the present paper.)

Presuming no knowledge of the sources from which the sera were obtained, we can make the following statements :-

(I) The two tests show a marked agreement in the results obtained.

(2) In our hands, the Kahn test gives more consistent results than the Wassermann when the two tests are repeated upon the same sera.

In some measure this is not unexpected. The Wassermann reaction involves more technical steps than the Kahn, and with each such extra step there is, despite the usual precautions, an increased risk of personal error. Again, upon each occasion that the Wassermann is performed the complement content of fresh guinea-pigs' serum has to be estimated, and slight variations will inevitably occur from day to day in the strength of the final solution used. Thus Wassermann reactions which at one test give a doubtful $(+)$ result might upon subsequent repeat tests fluctuate between a positive $(++)$ 


\section{KAHN AND WASSERMANN REACTION}

or complete negative, and so on. This will explain the frequency of minor variations, but the gross errors must reluctantly be attributed to personal error.

However, we do not believe that our Wassermann results are unusually variable when compared with those of other institutions. In fact, various concurrent series of tests would suggest that we maintain at least a good average.

It is a point definitely in favour of the Kahn that there is only one substance to be standardised, the antigen, and that this is a stable substance.

These repeat tests have thus been of considerable interest and value in that they have exposed this weakness, already suspected, in our Wassermann results, and have at the same time emphasised the desirability of performing two concurrent tests upon the same serum if only to act as a check upon laboratory errors.

A second reason for this double procedure, a difference in sensitivity in the two reactions, is illustrated by the observations which follow.

\section{Clinical Investigations}

We next decided to amplify and, if possible, assess these results by consulting the clinical records of a suitable group of cases. It appeared to us that those cases in which both reactions were negative or both definitely positive $(++$ or more) were less likely to yield useful information than those in which the original tests showed no check or a partial check.

Many sera in this group were received from outside institutions, or general practitioners, and the case histories were, for practical purposes, unobtainable. The remaining sera came from the venereal diseases clinic, the general wards and various out-patient departments of the hospital. We found it expedient to limit our search to the case records of the female patients attending the V.D. clinic, as these were most easily obtained. In all, I75 case abstracts were made. This number, although only about one-fifth of the total in the above group, consists of unselected and therefore probably representative cases.

These case abstracts were sorted into the following groups :-

(I) Cases for diagnosis. 


\section{BRITISH JOURNAL OF VENEREAL DISEASES}

(2) Early cases of syphilis observed from the commencement of treatment.

(3) Cases of syphilis that have received previous treatment.

(4) Cases of neuro-vascular syphilis.

(5) Cases of congenital syphilis.

\section{Group I._Cases for Diagnosis \\ Total Cases, 24}

Ten cases were positive to both reactions, but in one or other of the preliminary tests one reaction was only + . All these were cases of syphilis.

Two cases were still undiagnosed.

In eleven cases a non-specific reaction was obtained, seven with the Wassermann $(4$ of $+; 3$ of ++$)$ and four with the Kahn ( 2 of + ; 2 of ++ ).

Repeat tests upon a second sample of serum from these cases were invariably negative to both reactions.

These latter figures suggest that the Kahn is at least not more likely than the Wassermann to give nonspecific reactions. There is also a probability that the total number of non-specific Kahn reactions in the series of 5,000 was small.

The remaining case is recorded below in detail.

Case No. I986.-Female, æt. 20. Attended the clinic in 1927 with gonorrhœa.

The Wassermann was negative. During her treatment she must have exposed herself to fresh infection, as on October Ioth, I929, she had a typical chancre.

The subsequent progress was as follows :-

\begin{tabular}{|c|c|c|c|}
\hline Date. & Wassermann. & Kahn. & Treatment, etc. \\
\hline $\begin{array}{l}\text { 10.10.29. } \\
\text { 17.10.29. } \\
29.1 .30 . \\
\text { 12. } 4.30 . \\
27.10 .30 .\end{array}$ & $\begin{array}{c}\overline{+}++ \\
= \\
=\end{array}$ & $\begin{array}{c}++++ \\
++++ \\
- \\
-\end{array}$ & $\begin{array}{l}\text { N.A.B., 0.45 gm. } \\
\text { Bismuth and N.A.B. } \\
\text { Acetylarsan. }\end{array}$ \\
\hline
\end{tabular}

It will be observed that the Kahn reaction became positive before the Wassermann. 


\section{KAHN AND WASSERMANN REACTION}

Group II.-Early Cases of Syphilis observed from the Commencement of Treatment

Total Cases, 4.

Although there are only four cases in this group, all show the same phenomenon in a clear-cut manner; that is, a definite lag of some months before the Kahn follows the Wassermann and becomes negative.

Illustrative Case No. 3024.-Female, æt. 20. At the first attendance this patient had an indolent indurated sore on the upper lip and a fading macular rash on the body and scalp.

\begin{tabular}{|c|c|c|c|}
\hline Date. & Wassermann. & Kahn. & Treatment, etc. \\
\hline $\begin{array}{l}\text { II. I. } 29 . \\
\text { I2. } 9.29 . \\
\text { IO.I0.29. } \\
\text { I2. } 3.30 . \\
\text { II.I2.30. } \\
5 . \quad 2.3 \text { I. }\end{array}$ & $\begin{array}{c}+++ \\
- \\
- \\
-\end{array}$ & $\begin{array}{c}++ \\
+ \\
++ \\
- \\
-\end{array}$ & $\begin{array}{l}\text { N.A.B., } 4.05 \text { gm. } \\
\text { Mercury. } \\
\text { Bismuth, I5 c.c. } \\
\text { N.A.B., } 4.05 \text { gm. } \\
\text { Bismuth, I5 c.c. } \\
\text { N.A.B. }\end{array}$ \\
\hline
\end{tabular}

GROUP III.-Cases of Syphilis that have received
Previous Treatment

Total Cases, II4

These cases were immediately sub-grouped into the following :-

(I) Those showing almost identical variations in the strength of the Kahn and Wassermann results-3I cases.

Illustrative Case No. 825.-Female, æt. 40. Attended first in June, I925. For one year had had a tender swelling in the left leg. X-ray showed periostitis and superficial caries of the tibia.

\begin{tabular}{|c|c|c|c|}
\hline Date. & Wassermann. & Kahn. & Treatment, etc. \\
\hline $\begin{array}{r}\text { I9. } 6.25 . \\
\\
\text { I.I2.27. } \\
\text { I2. } 4.28 . \\
28.2 .29 . \\
\text { I7. } 3.29 . \\
\text { 30. } 5.29 . \\
27.6 .29 . \\
5.12 .29 . \\
\text { I0.10.30. }\end{array}$ & $\begin{array}{c}+++ \\
++ \\
- \\
++ \\
++ \\
++ \\
++ \\
++ \\
+\end{array}$ & $\begin{array}{c}+++ \\
++++ \\
+++ \\
+++ \\
+ \\
-\end{array}$ & $\begin{array}{l}\text { Bismostab N.A.B. } \\
\text { Repeated courses. } \\
\text { N.A.B. } \\
\text { Mercury. } \\
\text { N.A.B., } 4.05 \text { gm. } \\
\text { Mercury. } \\
\text { Mercury. }\end{array}$ \\
\hline
\end{tabular}




\section{BRITISH JOURNAL OF VENEREAL DISEASES}

(2) Those showing a tendency for the Wassermann to be stronger, or more persistent than the Kahn7 cases.

Illustrative Case No. 2184.-Female, æt. 34. Attended in December, 1927, with a granulomatous area on the back of the neck. No previous symptoms. Husband admits infection.

\begin{tabular}{|c|c|c|c|}
\hline Date. & Wassermann. & Kahn. & Treatment, etc. \\
\hline $\begin{array}{r}20.12 .27 . \\
\text { I. } 3.28 . \\
2.8 .28 . \\
27.12 .28 . \\
2.4 .29 . \\
\text { I8. } 7.29 . \\
\text { I6. } 8.29 . \\
7.11 .29 . \\
\text { I0. } 4.30 .\end{array}$ & $\begin{array}{c}+++ \\
+ \\
+ \\
++ \\
++++ \\
+ \\
++ \\
++ \\
+\end{array}$ & $\begin{array}{l}+ \\
++ \\
-\end{array}$ & $\begin{array}{l}\text { N.A.B., } 4.05 \mathrm{gm} . \\
\text { N.A.B., } 3.6 \mathrm{gm} . \\
\text { N.A.B., } 3.75 \mathrm{gm} \text {. } \\
\text { Pot. Iod. } \\
\text { Bismuth, } 8.5 \text { c.c. } \\
\text { N.A.B. } \\
\text { N.A.B. } \\
\text { Bismuth. }\end{array}$ \\
\hline
\end{tabular}

(3) Those showing a tendency for the Kahn to be stronger, or more persistent, than the Wassermann76 cases.

Illustrative Case No. 2803.-Female, æt. 38. Tertiary syphilis.

\begin{tabular}{c|c|c|l}
\hline \multicolumn{1}{c|}{ Date. } & Wassermann. & Kahn. & \multicolumn{1}{|c}{ Treatment, etc. } \\
\cline { 2 - 3 } & & & \\
\cline { 2 - 3 } 27.12.28. & ++++ & & N.A.B. (Course). \\
21. 2.29. & ++ & ++ & N.A.B. \\
I4. 3.29. & ++++ & & N.A.B. \\
25. 4.29. & - & ++ & Neotrepol. \\
23.10.29. & - & ++++ & Mercury. \\
I. I.30. & - & - & Bistovol. \\
9. 8.30. & - & - & \\
8.10.30. & - & + & \\
\hline
\end{tabular}

Illustrative Case No. I897.-Female, æt. 30. No symptoms. Had child with congenital syphilis. 


\section{KAHN AND WASSERMANN REACTION}

\begin{tabular}{r|c|c|l}
\hline \multicolumn{1}{c|}{ Date. } & Wassermann. & Kahn. & \multicolumn{1}{|c}{ Treatment, etc. } \\
\cline { 2 - 4 } I3. 8.27. & ++++ & & N.A.B., Bistovol, etc. \\
I9.II.28. & - & & N.A.B. and Bismuth. \\
9. 3.29. & + & ++ & N. \\
23. 8.29. & - & -+ & Bistovol, 24 c.c. \\
I.II.29. & - & - & \\
28. 2.30. & - & - & N.A.B. (Course). \\
24. 8.30. & + & +++ & \\
3.I0.30. & + & & \\
\hline
\end{tabular}

Illustrative Case No. I875.-Female, æt. 24. Secondary syphilis in March, I927.

\begin{tabular}{|c|c|c|c|}
\hline Date. & Wassermann. & Kahn. & Treatment, etc. \\
\hline $\begin{array}{l}\text { II. } 8.27 . \\
\text { I2.II. } 27 .\end{array}$ & +++ & & $\begin{array}{l}\text { N.A.B., 4.05 gm. } \\
\text { N.A.B. } \\
\text { Mercury. } \\
\text { Pot. Iod. }\end{array}$ \\
\hline $\begin{array}{l}\text { 7.I2.28. } \\
6.9 .29 .\end{array}$ & $\overline{t+}+$ & ++++ & \\
\hline 20. 9.29 & & ++++ & $\begin{array}{l}\text { N.A.B., } 0.3 \text { gm. } \\
\text { (Provocative). }\end{array}$ \\
\hline 25.10 .29 & + & $\begin{array}{c}+++ \\
++++\end{array}$ & N.A.B., 4.05 gm. \\
\hline & & & N.A.B., 4.05 gm. \\
\hline 9.4 .30$. & - & & $\begin{array}{l}\text { Bismostab, } 6 \text { c.c. } \\
\text { N.A.B., } 4.2 \text { gm. }\end{array}$ \\
\hline I2.I2.30. & - & + & \\
\hline
\end{tabular}

It must also be stated that the seven cases in subgroup 2 gave only slight differences in the two reactions, the case given as an illustration being the most marked of all ; whilst the differences in sub-group 3 were, in at least 50 per cent. of cases, very definite.

The fact suggested by the other groups is here definitely established, that in a large percentage of cases the Kahn reaction remains stronger or positive for a longer period than the Wassermann in cases of syphilis undergoing treatment. 


\section{BRITISH JOURNAL OF VENEREAL DISEASES}

\section{GROUP IV.-Neuro-vascular Syphilis \\ Total Cases, I3}

All these cases were diagnosed as tabes (two as latent). Three cases show more or less identical reactions.

Ten cases gave a more persistent or stronger Kahn reaction.

Illustrative Case No. 2720.-Female, æt. 30. Eleven years ago had eighteen months' course of injections for secondary syphilis. Complains now of failing vision in the right eye. Pupils unequal, fixed, reacting to neither light nor accommodation.

\begin{tabular}{|c|c|c|c|}
\hline Date. & Wassermann. & Kahn. & Treatment, etc. \\
\hline $\begin{aligned} & 23 . \text { I0.28. } \\
& \text { I.II. } 28 . \\
& 29 . 4.29 . \\
& 6 . 5 \cdot 29 . \\
& \\
& 7 . 2.30 .\end{aligned}$ & $\begin{array}{c}+ \\
\text { C.S.F. }++++ \\
++ \\
- \\
+\end{array}$ & $\begin{array}{c}++ \\
+++ \\
++++\end{array}$ & $\begin{array}{l}\text { Lange } 333100000 \\
\text { Bismostab, I5 c.c. } \\
\text { N.A.B., } 0 \cdot 3 \text { gm. } \\
\text { N.A.B., } 3 \cdot 6 \text { gm. } \\
\text { Bismostab, I5 c.c. }\end{array}$ \\
\hline
\end{tabular}

Illustrative Case No. 2730.-Female, æt. 32. Diagnosed as latent tabes. Pupils doubtful Argyll Robertson. Area of analgesia of tabetic distribution; mentality normal. Knee jerks-present. Rhomberg's sign-negative.

\begin{tabular}{|c|c|c|c|}
\hline Date. & Wassermann. & Kahn. & Treatment, etc. \\
\hline $\begin{array}{r}\text { 30.10.28. } \\
\text { I9. 9.29. } \\
\text { 3. I2.29. } \\
\text { I0. } 3.30 .\end{array}$ & $\begin{array}{l}- \\
- \\
-\end{array}$ & $\begin{array}{c}+++ \\
++ \\
++\end{array}$ & $\begin{array}{l}\text { N.A.B. ( } 2 \text { courses). } \\
\text { Bismostab, I2 c.c. } \\
\text { N.A.B., } 4.2 \text { gm. }\end{array}$ \\
\hline
\end{tabular}

Group V.-Congenital Syphilis

Total Cases, 20.

These cases were of various ages, and included six cases of interstitial keratitis and one of juvenile tabes. 


\section{KAHN AND WASSERMANN REACTION}

Six cases gave similar reactions, or slight variations, sometimes the Kahn stronger, sometimes the Wassermann.

Seven cases showed a slight tendency to be Wassermann positive.

Illustrative Case No. 8I7.-Female, æt. 5. No stigmata of congenital syphilis, but father had old infection and one older sister has a spastic paraplegia and $\mathrm{a}++++$ Wassermann. Numerous Wassermann tests done upon this patient from June, I925, until October, I928, have usually given + readings, but occasionally the result has been negative or $\mathrm{a}++$.

\begin{tabular}{c|c|c|c}
\hline Date. & Wassermann. & Kahn. & Treatment, etc. \\
\hline II. 5.29. & + & - & \\
I0. 8.29. & - & - & \\
I7. 2.30. & ++ & - & \\
I7. 6.30. & - & - & \\
II.10.30. & ++ & - & \\
\hline
\end{tabular}

Eight cases were definitely liable to give positive Kahns and negative Wassermanns.

Illustrative Case No. I352.-Female, æt. 35. Has attended Moorfields Eye Hospital for thirty years. Has typical lesions of congenital syphilis, including interstitial keratitis of the left eye. The right eye was operated upon in youth for cataract.

\begin{tabular}{|c|c|c|c|}
\hline Date. & Wassermann. & Kahn. & Treatment, etc. \\
\hline 9. 8.26 & ++++ & & $\begin{array}{l}\text { Bistovol. } \\
\text { Mercury. } \\
\text { Pot. Iod. } \\
\text { Repeated courses. }\end{array}$ \\
\hline $\begin{array}{l}\text { I8.I0.28. } \\
\text { I8. } 3.29 . \\
8.5 .29 \\
\text { 3.I2.29. } \\
\text { I7.I0.30. }\end{array}$ & $\begin{array}{l}\frac{+}{++} \\
-\end{array}$ & $\begin{array}{c}++ \\
+++ \\
++ \\
++++\end{array}$ & Bistovol, 30 c.c. \\
\hline
\end{tabular}




\section{BRITISH JOURNAL OF VENEREAL DISEASES}

\section{Discussion}

The foregoing observations can be summarised as follows :-

(I) The number of non-specific Kahn reactions is small, certainly not more than in the case of the Wassermann.

(2) The Kahn reaction is more sensitive than the Wassermann as :-

(a) In early cases undergoing treatment the Kahn continues to give positive reactions some months after the Wassermann has become negative.

(b) In cases undergoing prolonged treatment, and in latent cases, the Kahn is invariably stronger or more persistently positive than the Wassermann.

(3) We have found but little evidence that the Wassermann tends to be positive when the Kahn is negative. The only group that showed such a tendency to any appreciable degree was that consisting of the cases of congenital syphilis. But even here the reactions were almost entirely of weak type $(+$ or ++$)$.

It has been suggested that the factors responsible for the complement fixation reaction and the precipitation reaction are not identical. Whatever the biochemical evidence for this conception, our clinical investigations do not lend it support. If such was the case it would have been expected that a greater number of positive Wassermanns would have occurred in sera showing negative Kahns. Actually, only eighty-two sera came into this group, and in our repeat series of tests 78 per cent. of these became Wassermann negative. This means that the actual percentage of such cases in the series of 5,000 was only $0 \cdot 4$. The converse, as has been seen, was much more frequent.

The clinical evidence suggests, then, that the Kahn is definitely more sensitive than the Wassermann to syphilitic or anti-syphilitic substances in the blood, but not that a different factor is responsible.

From the point of view of laboratory diagnosis, there is to us little doubt that this gives a definite bias in favour of the Kahn, and this is increased by the smaller chance of personal error in the performance of the test.

The next point that arises is the comparative value of II6 


\section{KAHN AND WASSERMANN REACTION}

the tests as indicators of the degree of success in treatment. We have not intended to come to definite conclusions on this matter, as our investigations extend over too short a period. After some years' further comparison we shall be in a better position to express an opinion. Again, until the biochemical nature and the infective or immunological significance of the reacting substances to these tests is understood, this problem can never be adequately solved.

Nevertheless, we feel justified in making the following suggestions :-

A negative Wassermann does not necessarily mean a complete cure, neither does a persistent positive Wassermann necessarily imply that the patient will not be free from further symptoms, but for practical purposes the reaction is used as an indication of the success of treatment. This implies that, amongst other things, antisyphilitic measures are expected to remove the substances that give rise to the Wassermann reaction from the blood stream. Now, it has been shown that the Kahn is more specifically sensitive to these substances, and should be accepted to this extent as a more reliable indication of the efficiency of treatment and the degree of " cure" in the majority of cases. One case in our series not quoted in detail above is an excellent illustration of this point.

A female, æt 55, who had manifestations of secondary syphilis some twenty-five years ago, had no other treatment than a short course of mercury and iodides. During our tests four samples of serum were taken, and each showed a negative Wassermann and $\mathrm{a}++++\mathrm{Kahn}$. Whether or no this patient eventually developed neurosyphilis, there can be little doubt that she has not been cured, and equally little doubt that the Kahn gave a better indication than the Wassermann of the results of her previous treatment.

For the present the clinicians must use their own judgment in interpretation, and perhaps the quantitative Kahn test may give some assistance.

With regard to the numerous other flocculation tests used in the sero diagnosis of syphilis, attempts are being made both to simplify their technique and to increase their sensitivity. Of these we have had no personal experience, but would conclude from the literature, 


\section{BRITISH JOURNAL OF VENEREAL DISEASES}

especially the League of Nations report, that the Kahn at the rnoment holds the field.

\section{Technical Notes}

The Kahn tests in this series were performed with three batches of antigen, made according to the instructions given in Stitt's " Practical Bacteriology." "Difco" powdered beef heart was used. We experienced no difficulty in obtaining suitable antigen.

Precautions were taken to ensure consistent interpretation of readings, and also to prevent any possible knowledge of other results obtained with any particular serum with either test.

The results were read after twenty-four hours at room temperature, a concave mirror being used to magnify the tubes.

The following difficulties occurred :-

(I) $14 / 1 / 29$. The pipettes used for titrating the sera were fresh from the steriliser and still hot to the touch. The shortage of pipettes had not been noticed until the antigen had been titrated, and in order to comply with the twenty minutes' time limit for performing the test, we proceeded. The results were useless.

(2) $20-22 / 2 / 29$. The first set of tests done during the great frost of this time were unsatisfactory, and upon examining the antigen we found that the cholesterol had crystallised out. The antigen was gently warmed with agitation before use on subsequent days, and the results became satisfactory.

(3) On five occasions a series of consecutive tubes, usually those in the middle row, showed a fluffy deposit, which upon shaking became broken up into small particles, hardly visible to the naked eye. We have no explanation of this phenomenon.

\section{CONCLUSIONS}

(I) The Kahn test is less subject to laboratory errors than the Wassermann.

(2) The Kahn test is more sensitive than the Wassermann to syphilitic substances in the blood.

(3) The Kahn test gives a smaller number of nonspecific reactions than the Wassermann. 


\section{KAHN AND WASSERMANN REACTION}

(4) It is advisable to perform two concurrent tests upon all sera, firstly to act as a check upon laboratory errors, and secondly because of variations in sensitivity of the reactions.

We wish to express our thanks to Mr. V. E. Lloyd and Miss M. Rawlins, of the V.D. clinic, for access to the case records, and our gratitude to Professor Eyre for his helpful criticism, and to Messrs. Clark and Walters, of the technical staff, for their help in the preparation and performance of the tests. 